\title{
Nonparametric tests of strike price and expiration bias in the implied volatility of the South African All Share Index Future Contract
}

\author{
Ralf Wandmacher \\ Department of Statistical Sciences, University of Cape Town, Private Bag, Rondebosch, 7701 Republic of South Africa \\ RalfW@maths.uct.ac.za. \\ David J. Bradfield* \\ Department of Statistical Sciences, University of Cape Town, Private Bag, Rondebosch, 7701 Republic of South Africa \\ DBrad@maths.uct.ac.za.
}

\begin{abstract}
In this article we assess the appropriateness of the constant volatility assumption required by the Black (1976) option pricing model for options on the All Share Index future. The assessment uses similar nonparametric tests as implemented in Rubinstein for data recorded over the 1992 to 1996 period. In the nonparametric tests we focus on the examination of constant volatility across both striking prices as well as expiration dates. The nonparametric tests are not only based on traditional measures of statistical significance to examine the constant volatility assumption, but also utilize a measure of economic importance to assess the practical usefulness of the results. Our empirical results of both measures suggest that the assumption of constant volatility is inappropriate for options on the All Share Index future. Our results point to a pattern of rising volatility with increasing time to expiration and a higher volatility for out-of-the-money options compared to at-the-money options. This evidence is consistent with evidence in international markets found in the USA and the Netherlands.
\end{abstract}

*To whom correspondence should be addressed.

\section{Introduction}

Options on individual shares have been traded in the over-the-counter (OTC) market in South Africa since the end of the last century (Payne, 1980). Currently, options on bonds, stocks, the Rand, and index futures trade in the financial division of the South African Futures Exchange (SAFEX). Of these, American options on index futures are the most popular contracts, with the option contracts on the All Share Index (ALSI) future being the most liquid. As a consequence our research on volatility in this article focusses on these ALSI option contracts.

We scrutinize the Black (1976) model' implemented by SAFEX $^{2}$ for the pricing of options in the South African environment. In particular, we examine one of the important assumptions underlying the model, namely the assumption of constant volatility. The Black (1976) model and its ancestor, the Black \& Scholes (1973) model, assume constant volatility across strike prices and expiration dates. Our aim in this article is therefore to test this constant volatility assumption for options on ALSI futures. We do this by assuming as null hypothesis constant volatility across strike prices and across expiration dates. The volatility tested is calculated from option prices traded on the ALSI over the period from 1992 to 1996 . This volatility implicit in the option prices is henceforth referred to as the implied volatility.

Evidence in international literature reveals that implied volatilities differ across strike prices ${ }^{3}$ (see for example Latané \& Rendleman, 1976; Chiras \& Manaster, 1978; and Schmalensee \& Trippi, 1978). More recently, Rubinstein (1985) not only confirms these findings in the USA, but he additionally observes that implied volatilities also differ across expiration dates. ${ }^{4}$ Moreover, Rubinstein (1985) finds that the observed striking price bias and the expiration bias are statistically significant. Our article also differentiates between the striking price bias and the expiration bias and implements similar implied volatility tests (as in Rubinstein, 1985) in the South African environment.

Wandmacher \& Bradfield (1997) conduct a descriptive analysis on estimates of implied volatilities in the South African derivatives market and conclude that implied volatilities have a 'smile' appearance across strike prices. They therefore tentatively reject the assumption of constant volatility. However, their methodology hinges to some extent upon the appropriateness of the model used in the estimation of the implied volatilities. In this article we avoid this problem by leaving out the estimation of implied volatility and use a nonparametric methodology developed by Rubinstein (1985) instead. Furthermore, in this article we tackle the testing of the constant volatility more formally by conducting tests of significance.

The advantage of nonparametric tests is that they are 'distribution-free' in the sense that they assume nothing about the underlying population from which the sample is drawn. The nonparametric methodology is further implemented in several papers (see for example Sheikh, 1991; and Heynen, 1994) and has become a standard method for tests of implied volatility. To our knowledge this nonparametric methodology has not been implemented on American options on futures in the South African environment.

The article is organized as follows. First, we describe the data and the procedures to scrutinize it (second section). The third section contains an outline of the methodology of the research. The empirical evidence is presented in the fourth section, and finally section five summarizes and concludes the research findings. 


\section{Data}

The data for this empirical research consists of reported trades for high, low, first and last trading prices for options and futures on the ALSI and was downloaded from the SAFEX website.s The captured data consists of prices traded at SAFEX over the period 16 October 1992 to 31 December 1996. In this period, the underlying index changed from a so-called $80 \%$ market capitalisation index to an index with 40 shares. This new index (with typically smaller component holdings) has been in existence since 18 June 19956.

We partially follow Rubinstein's (1985) approach for selecting the trading data. A data 'cleaning' procedure is necessary for the prevention of arbitrage violations and mistake trades. We discuss these briefly below.

\section{Arbitrage violation}

One kind of arbitrage violation results when implied volatilities become zero or negative. The existence of negative or zero implied volatilities are not feasible by the definition of the underlying option price models because such an implied volatility value suggests that a risk-free profit is possible. The option is valued below the intrinsic value if the volatility is below zero so that an American option can immediately be exercised with a profit, because the exercise value will be higher than the option premium. Such arbitrage violations have to be excluded from the data to prevent a distortion of the data.

\section{Mistake trades}

A trade is classified as a mistake trade when the implied volatility is far beyond the regular volatility. A standard deviation in excess of $150 \%$ per annum is typically constituting a mistake trade. The second condition for mistake trades is that the trades at one day are followed by the same trade (the same option price, nearly the same high irregular volatility, and the same volume of options recorded) on the next day. The impression is that these trades were a mistake on the first trading date and that these trades were neutralized with compensating trades on the next trading day. Such trades also have to be excluded from the data set to present a distortion of the data.

The ALSI data over the 1992-1996 period consisted of 35844 trading prices (see Table 1). This excludes 1020 trading prices which were identified as arbitrage violations and mistake trades and were consequently omitted from the data. Hence, only $2.77 \%$ of all ALSI trading prices were identified as arbitrage violations and mistake trades.

Table 1 provides a summary of the data in this research. The number of traded option series ${ }^{7}$ is divided into the following categories of trading prices: first, last, high, and low price. If only one trade was made in an option series, this trade is recorded as the first, last, high, and low price of the option series for this day. Additionally, the sum of all numbers of trading prices of the categories first, last, high, and low prices are calculated in the last column of Table 1 so that the research is based upon 35844 trading prices

Below, we present the methodology for the further research.

\section{Table 1 Data categorised into trading classes}

The data is reported for the ALSI after screening for arbitrage violations and mistake trades in the period 16 October 1992 to 31 December 199. The column option series is the sum of option series for each trading day over all trading days (1066). Furthermore, the trades are differentiated into first, last, high, and low prices and the number of trades are summed up to the total number of available trading prices in the last column. If only one trade took place in an option series for a particular trading day, the price of this trade would be recorded as first, last, high and low price for the particular day.

\begin{tabular}{ccccccc}
\hline Index & Option & \multicolumn{4}{c}{ Trades } & Total of \\
\hline & Series & First (1) & Last (2) & High (3) & Low (4) & (1) to (4) \\
\hline ALSI & 9216 & 8981 & 8999 & 8820 & 9044 & 35844 \\
\hline
\end{tabular}

\section{Methodology}

The objective of the nonparametric tests is to examine analytically the null hypothesis of constant volatility across strike prices and expiration dates as required by the Black (1976) model. The results of the nonparametric tests are presented in the form of tables for the time-to-expiration bias test as well as for the striking price bias test.

This research therefore applies the nonparametric approach of Rubinstein (1985) to analyse the implied volatility across strike prices and expiration dates. However, due to the different environment in South Africa, the nonparametric tests require modification. The two main differences are summarized below:

1. The nonparametric research of implied volatilities by Rubinstein (1985), Sheikh (1991), and Heynen (1994) was only performed for options where the underlying asset is itself a non-derivative (Rubinstein [1985] examines options on shares, Sheikh [1991] investigates options on the S\&P 100 index, and Heynen [1994] analyses options on the Dutch European Options Exchange Index). In the South African environment, only options on futures (that is a derivative underlying) have a sufficient history of trading to conduct such an analysis. The influence of the derivative underlying on the analysis is explained in the appendix under the heading 'South African modifications'.

2. The studies by Rubinstein (1985), Sheikh (1991), and Heynen (1994) only implement data from call options (that cannot be exercised prematurely). Instead, we utilize a data set where the call and put data are combined because early exercise is not profitable in the South African environment due to the applied mark-to-market procedure for the option price at SAFEX. * Furthermore, we also present results for an additional two data sets having call and put data partitioned separately.

Moreover, the Black (1976) model applied in South Africa represents a further significant simplification because the interest rate is not taken account of in the model. Hence our results are immune from the biases of incorrectly approximated interest rates, whilst the results of several of the above-mentioned studies may be affected by such a problem.

Furthermore, the use of futures as underlying assets has one important advantage compared to non-derivative underlyings in that the dividend calculation and estimation are not required. The dividend estimation is very costly with 
large data sets and is a source of many approximation errors that are avoided by the use of derivative underlyings as in our ensuing analysis.

Having discussed the major differences to the prior research above, we focus below on the construction of the nonparametric tests. A first step in the construction of nonparametric tests is the categorisation of each option price as a function of the ratio of strike price to future price and time to expiration. Details of the definition of the categories are similar to Rubinstein (1985), but are modified for the South African environment. These details are relegated to the appendix and are discussed under the heading 'Category definitions'.

The categorised option prices are required to identify 'pairs' (as described in Rubinstein, 1985) for the nonparametric tests. A pair for the time-to-expiration bias test is defined as two option prices that are observed at the same date in the same constant price interval of the same underlying and that have the same strike price, but that have different expiration dates. A pair for the striking price bias test is defined as two option prices that are observed at the same date in the same constant price interval of the same underlying and that have the same expiration date, but that have different strike prices. Each option price is only used once for each nonparametric test.

Both definitions of pairs for the time-to-expiration bias test and for the striking price bias test require modifications for the South African environment. These modifications are also explained in detail in the appendix under the heading 'South African modification'.

The number of pairs in each data set is shown in Table 2, where the pairs of the ALSI are calculated for the call and put data combined, the call data separately, and the put data separately. We observe that 3128 pairs are defined for the time-to-expiration bias test compared to 6439 pairs for the striking price bias test in the combined call and put data set.

Henceforth, we follow Rubinstein's (1985) techniques ${ }^{9}$ for the calculation of the nonparametric test results of the time-to-expiration bias test (the striking price bias test). The test methodology contains two components. First, a probability, presented by $p$, is calculated assuming the null hypothesis of a constant volatility is true. According to Rubinstein (1985) the probability, p, is computed from the equation:

$$
p=1-N\left(\frac{(S h+0.5)-(T /(n 2))}{\sqrt{(T n) / 2}}\right)
$$

where $S h$ is the number of pairs that have a higher implied volatility with a shorter maturity (with a lower ratio of

\begin{tabular}{|c|c|c|c|}
\hline \multicolumn{4}{|c|}{$\begin{array}{l}\text { The numbers of pairs are shown for the three data sets on the ALSI. Both } \\
\text { the pairs for the time-to-expirution bias test and the pairs for the striking } \\
\text { price bias test are displayed. }\end{array}$} \\
\hline $\begin{array}{l}\text { Nonparametric } \\
\text { test } \\
\end{array}$ & $\begin{array}{l}\text { Combined } \\
\text { call and put }\end{array}$ & $\begin{array}{c}\text { Data set } \\
\text { call }\end{array}$ & Put \\
\hline Time-to-expiration bias & 3128 & 1212 & 863 \\
\hline Striking price bias & 6439 & 3851 & 2840 \\
\hline
\end{tabular}

strike price to future price). The total number of pairs is denoted with $\mathrm{Tn}$ while $\mathrm{N}($.) represents the standard normal distribution function.

The resulting probability, $\mathrm{p}$, should be equal to 0.5 according to the null hypothesis of constant volatility. A probability, p, close to 0 gives evidence that the shorter maturity (the lower ratio of strike price to future price) has a higher implied volatility. A probability, p, close to 1 by contrast, implies that the longer maturity (higher ratio of strike price to future price) has a higher implied volatility. Under a standard $5 \%$ significance level test ${ }^{10}$ we would reject the null hypothesis if the probability, $p$, is between 0 and 0.025 , or when it is between 0.975 and 1 .

The statistical significance test is supplemented by a second nonparametric test with a measure of economic importance. "According to Rubinstein (1985) the test for economic importance requires the median difference in implied volatilities to be zero in each comparison ${ }^{12}$ (under the null hypothesis of a constant volatility). Nevertheless, the median difference in implied volatilities has nothing to do with a bias from the Black option values. Hence, we equate the percentage differences between the traded option prices and their theoretical Black values for the two option prices in each pair. This is done by using the implied volatility as input variable. According to Rubinstein (1985) the solution of the equation (2) below results in a measure of economic importance, $\alpha$, (further discussed below).

$$
\frac{B_{1}^{\text {theo }}(\alpha)-P_{1}}{P_{1}}=\frac{P_{2} B_{2}^{\text {theo }}(\alpha)}{P_{2}}=0.01 \alpha
$$

where $P_{i}$ is the traded price for each option in the pair ( $i=$ $1,2)$ and $B_{1}^{\text {then }}$ is the theoretical option price of the Black (1976) model for the implied volatility, $\alpha$. The measure of economic importance is presented by $\alpha$.

The economic importance, $\alpha$, is the value that displays the minimum difference between the market price and the theoretical Black value for the option prices in a pair. The $\alpha$ is therefore the lower bound of economic bias in the Black (1976) model. In accordance with Rubinstein (1985) we use the median of the $\alpha$ 's for each comparison of pairs.

The null hypothesis implies that the probability, $p$ (measure of statistical significance) should be 0.5 and the $\alpha$ (measure of economic importance) should be zero. Although the rejection of the null hypothesis can only be based upon the statistical significance, the economic importance nevertheless provides additional information to assess the statistical significance for the practical use. We expand on this distinction below.

\section{Statistical significance and economic importance}

A result may be statistical significant but may still not be pronounced enough to be practically useful. Hence, a statistically significant result is perhaps not always sufficient for practical purposes. In such cases the computed measure of economic importance will be low. By contrast if the computed measure of economic importance is high, it would suggest that the statistically significant result is practically useful. ${ }^{13}$ 
Below, we implement the nonparametric tests and discuss their results.

\section{Empirical evidence}

The empinical evidence for the combined call and put data is presented in Table 3 for the time-to-expiration bias test and in Table 4 for the striking price bias test. Further evidence is presented in the appendix for the call data separately (Table A5 and Table A6 respectively) ${ }^{14}$ and the put data separately (Table A7 and Table A8 respectively).

Recognising that the presentation of our results in tabulation form are unavoidably complex we use similar table structures to those found in Rubinstein (1985), Sheikh (1991), and Heynen (1994). Due to this unavoidable complexity of the tables, we begin however with a brief explanation of their structure. Table 3 (Table A5 and Table A7 respectively) shows the results for the time-to-expiration bias test for three panels (10-90 versus 100-180, 10-90 versus 190-540, and 100-180 versus 190-540). The results for each panel are presented for each ratio of strike price to future price $(0.60-0.85,0.85-0.95,0.95-1.05,1.05-1.15$, and $1.15-1.40$ ) in Table 3 . The first column of each ratio of strike price to future price displays the total number of pairs (Tn) for a panel. The second column of each ratio of strike price to future price shows the value of the economic importance, $\alpha$, on the first line and the value of the probability, p, (or statistical significance) on the second line. Hence, the third column of each ratio of strike price to fu- ture price represents the number of pairs for each panel where the shorter maturity (Sh) has a higher implied volatility than the longer maturity. The first column value (Tn) and the third column value (Sh) are required in equation (1) to calculate the probability, p. This computed probability, $p$, is given as the second value in the second column.

Table 4 (and Table A6 and Table A8 respectively) summarizing the results of the striking price bias test is constructed in similar manner to Table 3 . The only differences are that ten panels exist $(0.60-0.85$ versus $0.85-0.95,0.60$ 0.85 versus $0.95-1.05$, ..., and $1.05-1.15$ versus $1.15-1.40$ ) and that the results for each panel are presented across days to expiration $(10-30,30-60,60-90,90-180,180-270$, >270). Hence, column one and two across days to expiration in Table 4 are defined analogous to Table 3 , whilst column three across days to expiration represents the number of pairs for each panel where the lower ratio of strike price to future price $(\mathrm{Sh})$ has a higher implied volatility than the higher ratio of strike price to future price.

Having focused on the structure of the tables we focus on the results in the tables.

We begin with a discussion of the results of the timeto-expiration bias test for the ALSI shown in Table 3. From Table 3 it is evident that the at-the-money ratios significantly rejects the null hypothesis at the $5 \%$ level because their probabilities are 1.00 (that is the longer time to expiration has the higher implied volatility). Additional to the statistical significance, the measure of economic importance is also large having values between 5.41 and 6.47 . Similar

Table 3 Nonparametric time-to-expiration bias test for the combined call and put data of the ALSI The test is carried out for nearly identical calls and puts only differing in their expiration dates for the period 16 October 1992 to 31 December 1996 .
The Tn columns give the total number of pairs and the Sh columns represent the number of pairs for which the shorter maturity has a higher implied
volatility. The first value in the middle column of each comparison displays the economic importance, $\alpha$, in percent and the second value given is the
staistical significance or probability, p.

\begin{tabular}{|c|c|c|c|c|c|c|c|c|c|c|}
\hline \multicolumn{11}{|c|}{ Strike $\div$ Future } \\
\hline & \multirow{2}{*}{\multicolumn{2}{|c|}{$\begin{array}{c}\text { deep out-of-the-money } \\
0.60-0.85\end{array}$}} & \multirow{2}{*}{\multicolumn{2}{|c|}{$\begin{array}{l}\text { out-of-the-money } \\
0.85-0.95\end{array}$}} & \multirow{2}{*}{\multicolumn{2}{|c|}{$\begin{array}{c}\text { at-the-money } \\
0.95-1.05\end{array}$}} & \multirow{2}{*}{\multicolumn{2}{|c|}{$\begin{array}{c}\text { in-the-money } \\
1.05-1.15\end{array}$}} & \multirow{2}{*}{\multicolumn{2}{|c|}{$\begin{array}{c}\text { deep in-the money } \\
1.15-1.40\end{array}$}} \\
\hline & & & & & & & & & & \\
\hline & Tn & Sh & Tn & Sh & Tn & Sh & $T \mathbf{n}$ & Sh & $\overline{T n}$ & Sh \\
\hline \multirow[t]{2}{*}{ Days to maturity } & \multicolumn{2}{|c|}{$\alpha$} & \multicolumn{2}{|c|}{$\alpha$} & \multicolumn{2}{|c|}{$\boldsymbol{\alpha}$} & \multicolumn{2}{|c|}{$\alpha$} & \multicolumn{2}{|c|}{$\alpha$} \\
\hline & \multicolumn{2}{|c|}{$\mathbf{p}$} & \multicolumn{2}{|c|}{$\mathbf{p}$} & \multicolumn{2}{|c|}{ p } & \multicolumn{2}{|c|}{$\mathbf{p}$} & \multicolumn{2}{|c|}{$\mathbf{p}$} \\
\hline $10-90$ & 0 & 0 & 29 & 11 & 609 & 137 & 16 & 10 & 0 & 0 \\
\hline vs. & \multicolumn{2}{|c|}{ NA } & \multicolumn{2}{|c|}{2.19} & \multicolumn{2}{|c|}{5.41} & \multicolumn{2}{|c|}{ NA } & \multicolumn{2}{|c|}{ NA } \\
\hline $100-180$ & \multicolumn{2}{|c|}{ NA } & \multicolumn{2}{|c|}{0.87} & \multicolumn{2}{|c|}{$1.00 * *$} & \multicolumn{2}{|c|}{ NA } & \multicolumn{2}{|c|}{ NA } \\
\hline $10-90$ & 16 & 16 & 112 & 60 & 972 & 461 & 86 & 30 & 5 & 0 \\
\hline vs. & \multicolumn{2}{|c|}{ NA } & \multicolumn{2}{|c|}{1.94} & \multicolumn{2}{|c|}{6.47} & \multicolumn{2}{|c|}{2.71} & \multicolumn{2}{|c|}{$\mathbf{N A}$} \\
\hline $190-540$ & \multicolumn{2}{|c|}{ NA } & \multicolumn{2}{|c|}{0.20} & \multicolumn{2}{|c|}{$1.00 * *$} & \multicolumn{2}{|c|}{$1.00 * *$} & & \\
\hline $100-180$ & 0 & 0 & 34 & 12 & 216 & 28 & 30 & 10 & 3 & 3 \\
\hline vs. & & & & & & & & & & \\
\hline $190-540$ & & & & & & & & & & \\
\hline
\end{tabular}

2. The ratio of strike price and future price headings would revert for a call (i.e. out-of-the-money becomes in-the-money and vice versa). However,

the in-the-momey pur (call) volatility is the same as the out-of-the-money call (put) volatility because of the put-call parity convention. Hence, we keep the headings consistent.

b.NA indicates a comparison with less than 20 pairs so that the economic and statistical significance tests are unreliable.

* Significantly different from 0.5 at the $10 \%$ level.

** Significantly differem from 0.5 at the $5 \%$ level. 
results can be observed for the call data separately in Table A5 and for the put data separately in Table A7. Such a pattern of a higher implied volatility for the longer time to maturity was also documented by Rubinstein (1985) for at-the-money options (in the first period's of his research).
Sheikh (1991) finds a similar pattern in one of three investigated subperiods of his research.

Furthermore, we observe in Table 3 that the statistical significance decreases from the at-the-money ratio to the in-the-money ratio (also in Table A5 and Table A7). See for

\section{Table 4 Nonparametric striking price bias test for the combined call and put data of the ALSI}

The test is carried out for nearly identical calls and puts only differing in the strike prices for the period 16 October 1992 to 31 Decernber 1996 . ithe Tn columns give the total number of pairs and the Sh columns represent the number of pairs for which the lower ratio of strike price to future price (strike $\div$ future) has a higher implied volatility. The first value in the middle column of each comparison displays the economic importance, $\alpha$, in percent and the second value is the statistical significance or probability, $p$.

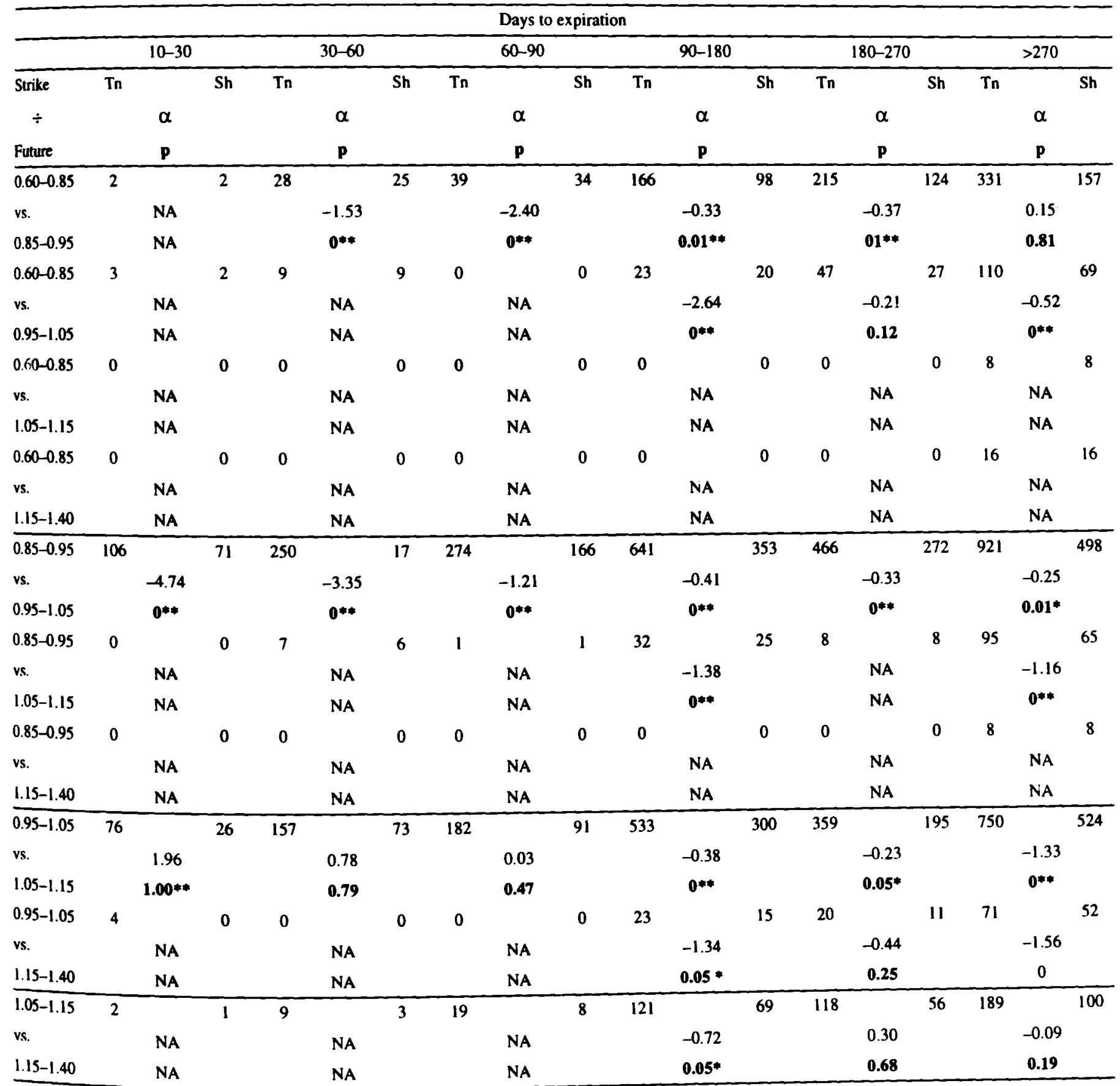

a. The ratio of strike price and future price headings would revert for a call (i.e. out-of-the-money becomes in-the-money and vice versa). However, the in-the-money put (call) volatility is the same as the out-of-the-money call (put) volatility because of the put call parity convention. Hence, we keep the headings consistent.

b. NA indicates a comparison with less than 20 pairs so that the economic and statistical significance tests are unreliable.

* Significantly different from 0.5 at the $10 \%$ level.

** Significantly different from 0.5 at the $5 \%$ level. 
example Table 3 where the statistical significance in the third panel (that is 100-180 versus 190-540) for the in-themoney ratio (that is $1.05-1.15$ ) is only statistically significant at the $10 \%$ level $(p=0.95)$. The economic importance also declines simultaneously with the decrease of the statistical significance and therefore indicates that the results of in-the-money options are less significant than the results of at-the-money options. The decrease of the statistical significance from the at-the-money to the in-the-money ratio is also observable in Rubinstein (1985) and Sheikh (1991).

Moreover, the statistical significance for the out-of-themoney ratio diminishes to insignificant results in Table 3 and Table A7 respectively. However, Table A5 shows one significant result at the $10 \%$ level for the out-of-the-money ratio with a probability of 0.03 (that is the shorter time to expiration has the higher implied volatility). Although this result is based upon a small sample $(\mathrm{Tn}=22)$, it indicates a substantial change in the implied volatility direction from the at-the-money ratio to the out-of-the-money ratio. This substantial change of the implied volatility implies that the at-the-money ratio and the out-of-the-money ratio have differing directions in time-to-expiration biases. Nevertheless, both ratios suggest the violation of the non-constant volatility assumption.

Concluding the discussion of the time-to-expiration bias test for the ALSI, the null hypothesis is rejected at a $5 \%$ significance level for the at-the-money ratio. The results of the in-the-money ratio suggest the rejection of the null hypothesis at the $10 \%$ significance level with exception of the third panel in Table A5. The results of the out-of-the-money ratio also suggest the rejection of the null hypothesis at the $10 \%$ significance level. Furthermore, the levels of the economic importance are consistent with the statistical significance results. From Table 3 it is evident that across the strike price to future price ratio (strike $\div$ future) the economic importance declines from having the highest value for the at-the-money ratio to lower values for the out-ofthe-money ratio and in-the-money ratio.

The above discussion dealt with the time-to-expiration bias test (in Table 3, Table A5, and Table A7). We continue the analysis of the striking price bias test below.

The results of the striking price bias test for the combined call and put data set is shown in Table 4, whilst the results for the separate call data and put data are shown in Table A6 and Table A8 in the appendix respectively.

It is evident in the three tables that the probabilities are mostly 0 or close to 0 (that is the lower ratio of strike price to future price has the higher implied volatility) and therefore highly statistically significant. The exceptions of these probabilities of 0 or close to 0 are observed across more than ' 180 days' to expiration (that is $180-270$ and $>270$ ) and in the at-the-money/in-the-money panel (that is 0.95 1.05 versus $1.05-1.15$ ).

For the combined call and put data in Table 4, the results of the at-the-money/in-the-money panel (that is 0.95-1.05 versus 1.05-1.15) show a decreasing probability as the time to expiration increases. For example the probability decreases from 1.00 to 0 across the ' $10-30$ ' to the ' $>270$

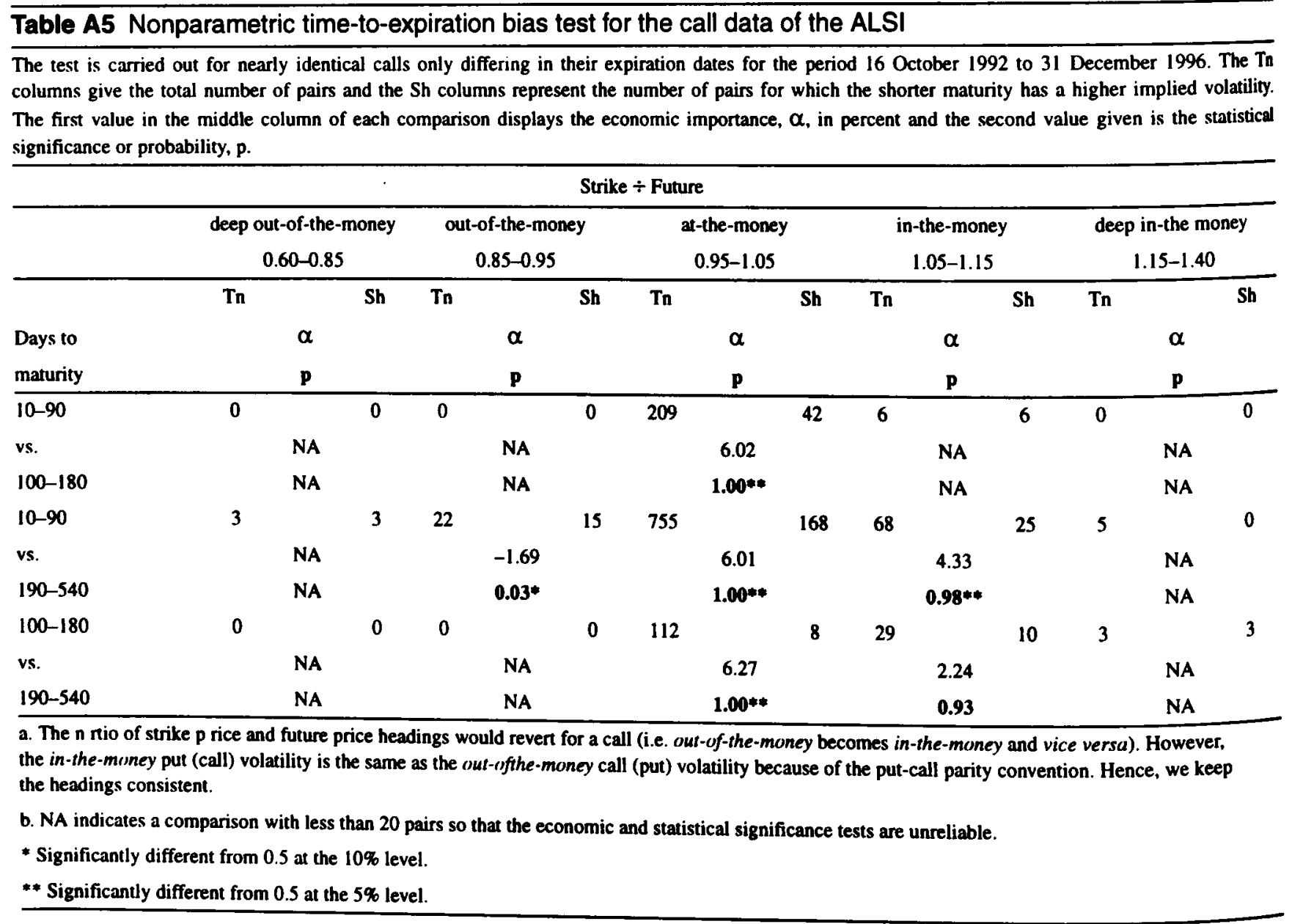


days' to expiration in Table 4 . The results $(1.00$ and 0$)$ are statistically significant at the $5 \%$ level and suggest to reject the null hypothesis of a constant volatility.

The 'more than 180 days' to expiration categories (that is $180-270$ and $>270$ ) show several statistically significant results at the $5 \%$ level but also a few insignificant results. It seems that with increasing time to expiration the results become less significant. This conclusion is supported by very low values for the economic importance for longer time to expirations. However, the economic importance ${ }^{16}$ also shows relatively small values for statistical significant results. Furthermore, our results are similar to the findings by Rubinstein (1985) (for his first period investigated).

The empirical results suggest that the lower ratio of strike price to future price has predominantly higher implied volatilities. These results become more pronounced in terms of the economic importance with declining ratios of strike prices to future prices and with decreasing time to expiration. Rubinstein's (1985) results also correspond favourably to our results.

In sum, we conclude that the lower ratio of strike price to future price generally has the higher implied volatility for the ALSI in South Africa, in particular for out-of-themoney comparisons (panels 1 to 7). Our results, however, are less pronounced than the 'volatility smiles' documented in Wandmacher \& Bradfield (1997). Nevertheless, we also observe that the pronunciation decreases for increasing time to expiration because the results become less significant (statistically and economically) with increasing time to expiration. Furthermore, the exception of a higher implied volatility for a higher ratio of strike price to future price for the at-the-money/in-the-money panel (that is 0.951.05 versus 1.05-1.15) with a short time to expiration seems significant and should be taken account of in option-pricing decisions. Finally, based on our results we reject the null hypothesis of constant volatilities across strike prices for options on ALSI futures in South Africa.

\section{Conclusion and summary}

The purpose of the nonparametric tests was to test the null hypothesis that the implied volatility is constant across strike prices and across expiration dates. Our results, based upon statistical significance and economic importance, suggest that the null hypothesis of constant volatility should be rejected. Furthermore, a distinction between the three data sets, the call, the put, and their combination was found to be unnecessary because no significant difference was found between them. The most important results are briefly summarized below.

The nonparametric time-to-expiration bias test revealed that the implied volatility generally increased with time to maturity in the at-the-money range for the ALSI. Similar results are found by Rubinstein (1985) and Sheikh (1991). Furthermore, we observed that the implied volatility is generally higher for the lower ratio of strike price to future price. Evidence in Heynen (1994) and Rubinstein (1985) also show similar results. Finally, we found that the pronounced effect of non-constant implied volatility decreases (that is becomes more constant) with increasing time to expiration.
A plausible explanation for why the higher implied volatility for lower ratios of strike price to future price is evident is because such options increased in value as a consequence of the market crash in October 1987. The expectation of large profits due to a large fall in market prices is consequently priced in the options by higher implied volatilities. Additionally, one might expect that the effect of higher implied volatilities would be more pronounced for a short time to expiration than for a long time to expiration. This is because a large fall in market prices tend to take place in a very short period of time (for example the market crash in 1987) so that an option with long time to expiration has a higher probability of the market recovery. Hence, the option with a long time to expiration has a less pronounced effect of volatilities across expiration dates. Finally, our observation from the time-to-expiration bias test that the increase of implied volatilities for at-the-money strikes may be explained by the additional risk of significant price movements the longer the time to expiration.

To our knowledge the methodological adaptations to derivative underlyings as opposed to traditional implementation on non-derivative underlying assets is the first of its kind. The advantage of implementing the nonparametric test methodology on options on futures is twofold. Firstly, no dividends have to be calculated or estimated. The widely used approximation of dividend yields instead of the discrete dividends is one of the problems that we avoid. Secondly, options on futures are mark-to-market and therefore are not influenced by any interest rate. Consequently, the use of approximate interest rates like the Treasury bills or the Bank bills are not required and approximation errors do not therefore occur. Furthermore, early exercise of the American options on futures is not optimal. Hence, all data can be used and does not have to be filtered because of the early exercise problems experienced by Rubinstein (1985).

Nevertheless, we allude to our data constraints and point out that the main weakness of our study is the non-simultaneous price problem. This non-simultaneous price problem arises because the price of the options and the price of the futures are not traded at the same time. Although we use the same trading classes for option and future prices, we cannot totally avoid this problem. Sheikh (1991) assumes that artificial prices are a further problem, especially for the daily mark-to-market products at the end of the day because market makers may try to influence their margin requirements by manipulating the closing bid and ask prices. ${ }^{17}$

In sum, our results reject the assumption of constant volatility required by the Black (1976) model for the South African environment. Our conclusion based on the results of the nonparametric tests adopted here are consistent with Wandmacher \& Bradfield (1997) (using a descriptive approach), strengthening the call for the rejection of the constant volatility assumption. Hence, the pricing of options in South Africa requires models that do not rely on the constant volatility assumption. 
Table A6 Nonparametric striking price bias test for the call data of the ALSI

The test is carried out for nearly identical calls only differing in the strike prices for the period 16 October 1992 to 31 December 1996 . The Tn columns give the total number of pairs and the Sh columns represent the number of pairs for which the lower ratio of strike price to future price (strike $\div$ future) has a higher implied volatility. The first value in the middle column of each comparison displays the economic importance, $\alpha$, in percent and the second value is the statistical significance or probability, $p$.

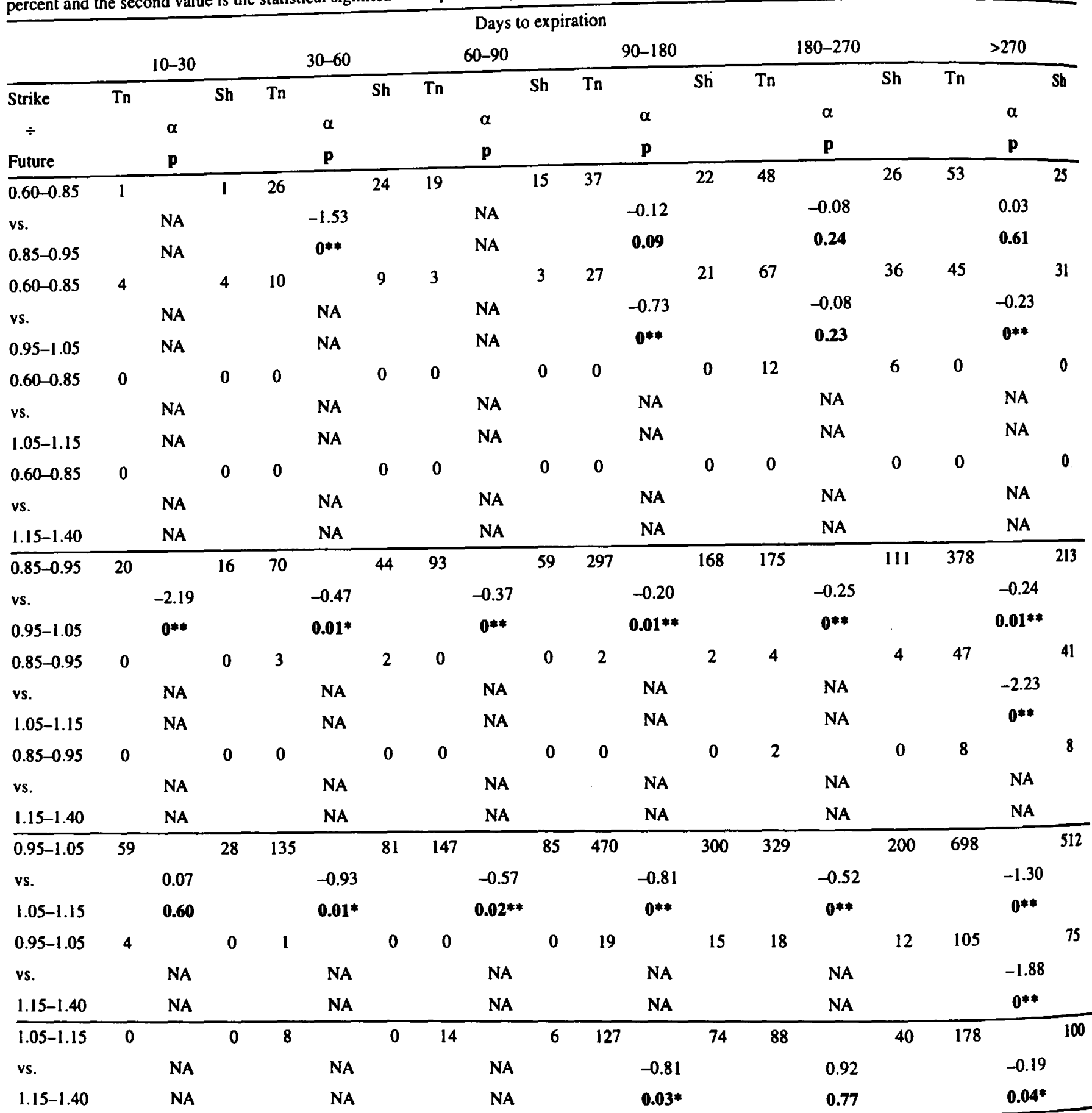

a. The ratio of strike price and future price headings would revert for a call (i.e. out-of-the-money becomes in-the-money and vice versa).

However, the in-the-money put (call) volatility is the same as the out-of-the-money call (put) volatility because of the put call parity convention.

Hence, we keep the headings consistent.

b. NA indicates a comparison with less than 20 pairs so that the economic and statistical signif cance tests are unreliable.

* Significantly different from 0.5 at the $10 \%$ level.

** Significantly different from 0.5 at the $5 \%$ level.

\section{Notes}

1. SAFEX references the Black (1976) model but actually uses a modification of this model for the mark-to-market of the option price characterised by Asay (1982) and analytically developed by Lieu (1990). We will furthermore refer to the model by SAFEX implemented as Black model, but as we pointed out this model is modified for the South African environment.

2. Kindly pointed out by Khonaye Penxa, Risk Management Department, SAFEX Clearing Company (SAFCON) and 
furthermore described in the option premium specification of the contract specifications for futures and options contracts published by SAFEX on http://www.safex.co.za.

3. Different implied volatilities across strike prices are further referred to as striking price bias, or as volatility smile, or as a 'volatility skew'.

4. Different implied volatilities across expiration dates are further referred to as time-to-expiration bias, or as a term structure, or a maturity bias.

5. The address of SAFEX homepage is http://www.safex.co.za.

6. Options and futures with maturities up until March 1996 were based on the $80 \%$ market capitalisation index. Subsequent to March 1996, options and futures have been based on the new index. A separation between the old and the new indices is deemed unnecessary for the purpose of this research because the behaviour of the two indices is nearly identical during the overlapping time between 15 June 1995 and 29 March 1996 (with a correlation of 0.9963 ).

7. An option series is defined here as the traded prices (first, low, high, and low) of one trading day for one particular strike and one particular expiration.

8. Margin yields market interest rates at SAFEX.

9. These techniques are also applied by Heynen (1994) and Sheikh (1991), although Sheikh (1991) gives an incorrect formula for the statistical significance test.

10. With a $10 \%$ significance level test we would reject the null hypothesis for probabilities, p, between 0 and 0.05 or 0.95 and 1.

11. The measure of economic importance is originally referred to as economic significance in Rubinstein (1985). The potential ambiguity between statistical significance and economic significance leads to the more cautious reference of economic importance.

12. For example a comparison between shorter and longer maturity with 10 pairs may reveal in each pair a difference in the implied volatility. The result for the comparison is the median of the differences in the implied volatility for the 10 pairs.

13. Furthermore, statistical insignificant results with either a low measure of economic importance or a high measure of economic importance are possible. Such results are defined as insignificant.

14. The prefix A stands for the appendix.

15. Rubinstein (1985) differentiates his research in two periods.

16. The economic importance may be questionable because of its frequent low value in the tables for the striking price bias test. Heynen (1994) compares the $\alpha$ with the bid-ask spread and only views $\alpha$ 's higher than $3 \%$ as significant. Rubinstein (1985) argues that the economic importance depends on the market participant and the purpose of the option. He also explains that $\alpha$ is only the minimum deviation from the Black value for both options in the pair, and that the economic importance is only designed to show the weakness of the assumption of constant volatility. We think that some market participants can already make riskless arbitrage profits with small deviations from zero in the option markets if almost all market participants calculate the option prices according to the Black model. Riskless arbitrage profits conflict with the assumption of constant volatility so that we can interpret low values of the economic importance as an indicator of inefficiency of the Black model.

17. The daily mark-to-market price is calculated as the mid-market price at the closing of trading at SAFEX.
18. The possibility of distortions in last trading days before expiration is solved with the omission of the last ten trading days. Heynen (1994) omits the last 15 trading days whereas Rubinstein (1985) and Sheikh (1991) omit the last 21 trading days before expiration.

\section{Acknowledgement}

The authors would like to thank two anonymous referees for helpful comments.

\section{References}

Asay, M. R. 1982. A note on the design of commodity option contracts, Journal of Futures Markets, 2(1): 1-7.

Black, F. 1976. The pricing of commodity contracts, Journal of Financial Economics, 3: 167-179.

Black. F. \& Scholes, M. 1973. The pricing of options and corporate liabilities, Journal of Political Economy, 81: 637-659.

Chiras, D.P. \& Manaster, S. 1978. The information content of option prices and a test of market efficiency, Journal of Financial Economics, 6: 213-234.

Heynen, R. 1994. An empirical investigation of observed smile patterns, Review of Futures Markets, 13: 317-353.

Latane, H. A. \& Rendleman, Jr., R.J. 1976. Standard deviations of stock price ratios implied in option prices, Journal of Finance, 31(2): 369-381.

Lieu, D. 1990. Option pricing with futures-style margining, Journal of Futures Markets, 10(4): 327-338.

Payne, A.F.T. 1980. Options trading, Investment Analysts Journal, 16: 23-27.

Rubinstein, M. 1985. Nonparametric tests of alternative option pricing models using all reported trades and quotes on the $\mathbf{3 0}$ most active CBOE option classes from August 23, 1976, through August 31, 1978, Journal of Finance, 40(2): 455-480.

Schmalensee, R. \& Trippi, R.R. 1978. Common stock volatility expectations implied by option premia, Journal of Finance, 33(1): 129-147.

Sheikh, A. M. 1991. Transaction data test of S\&P 100 call option pricing, Journal of Financial and Quantitative Analysis, 26(4): 459-475.

Wandmacher, R. \& Bradfield, D. 1997. On implied volatilities in the South African derivatives market, Working Paper, Department of Statistical Sciences. Cape Town: University of Cape Town.

\section{Appendix}

\section{Category definitions}

Details of the definition of the categories are modified in the South African environment for the time-to-expiration bias test and the striking price bias test. Both tests require ratios of strike price to future price that we therefore define as below:

1. Deep out-of-the-money $(0.60$ to 0.85$)$

2. Out-of-the-money ( 0.85 to 0.95$)$

3. At-the-money (0.95 to 1.05$)$

4. In-the-money (1.05 to 1.15$)$

5. Deep in-the-money (1.15 to 1.40 )

The definition of the time to expiration interval is different from Rubinstein (1985) because options at SAFEX have quarterly expiration dates compared to monthly expiration dates of the stock options in his research. Furthermore, only up to three different expirations were traded at SAFEX at the same time. As a consequence three intervals 
of time to expiration are chosen for the nonpararnetric time-to-expiration bias test'8:

1. nearest expiration (10 to 90 days)

2. middle expiration (100 to 180 days)

3. far expiration (190 to 540 days)

Additionally, we differentiate between the nonparametric time-to-expiration bias tests and striking price bias tests. Here, we differ from the other mentioned research (except Sheikh, 1991). The differentiation between nonparametric time-to-expiration bias tests and striking price bias test is essential to obtain a clearer impression of the market conditions. Hence, more time to expiration intervals are calculated for the nonparametric striking price bias tests but the last ten trading days before expiration are also omitted. The time to expiration intervals are

1. nearest expiration ( 10 to 30 days)

2. very near to expiration ( 30 to 60 days)

3. near to expiration ( 60 to 90 days)

4. middle expiration (90 to 180 days)

5. far expiration (180 to 270 days)

6. very far expiration (more than $\mathbf{2 7 0}$ days)

In sum, the ratios of strike price to future price and the time to expiration intervals produce 15 categories for the nonparametric time-to-expiration bias test and 30 categories for the nonparametric striking price bias test. Hence, each option price is sorted into one of the 15 categories for nonparametric time-to-expiration bias tests and into one of the 30 categories for nonparametric striking price bias tests.

\section{South African modifications}

Both the pair definition for the time-to-expiration bias tert and for the striking price bias test must be modified for the South African environment. The first modification applien to both tests.

Rubinstein (1985) implements rigorous defined criteris for both tests to prevent different trading times for option and underlying. We similarly use the same trading class for options and futures. The trading classes are defined as first last, high, and low trading price for each option and future price. Nevertheless, we must bear in mind that the use of trading classes is a relaxation of Rubinstein's (1985) rigorous criteria. However, the implemented trading classes may mean more noise in our data, but it also means a chance to refer to all traded data. Rubinstein's (1985) approach contains the danger that very important pieces of information are excluded because they do not match his stringent conditions for the data.

A second modification only concerns the time-to-expiration bias test. As mentioned, existing research applies the nonparametric tests only to non-derivative underlyings while we examine a derivative underlying (that is future) in this article. The difference between nonderivative underlyings (for example stock indices, stocks) and derivative underlyings (for example futures) is particularly important because of the definition of the pairs in the time-to-expiration bias test. The time-to-expiration bias test requires that the expiration dates be different but that the strike prices be the same. Rubinstein (1985) concludes implicitly that the

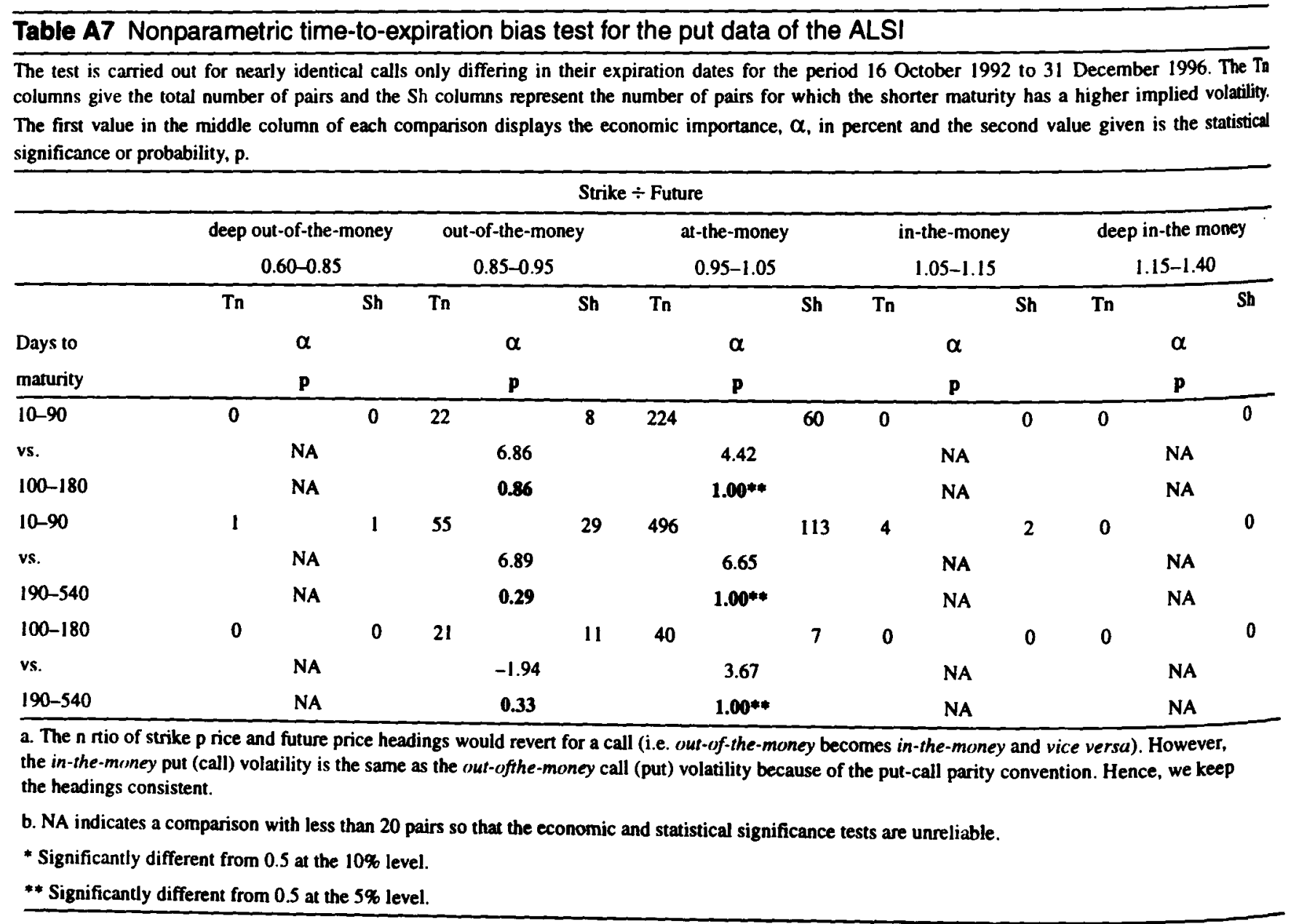


ratios of strike price to future price are also the same because of the same strike prices. Such a conclusion is only correct for non-derivative underlyings. Derivative underlyings, in particular futures, normally differ in their prices for different expiration dates. The problem with in the time-to- expiration bias test is that the ratio of strike price to future price ratios may differ from each other because of the price differences between the futures. Therefore, we use only pairs that have the same striking price ratio as an additional condition for the time-to-expiration bias test.

\section{Table A8 Nonparametric striking price bias test for the put data of the ALSI}

The test is carried out for nearly identical calls only differing in the strike prices for the period 16 October '92 to 31 December 1996 . The Tn columns give the total number of pairs and the $S h$ columns represent the number of pairs for which the lower ratio of strike price to future price (strike $\div$ future) has a higher implied volatility. The first value in the middle column of each comparison displays the economic importance, $\alpha$, in percent and the second value is the statistical significance or probability, $p$.

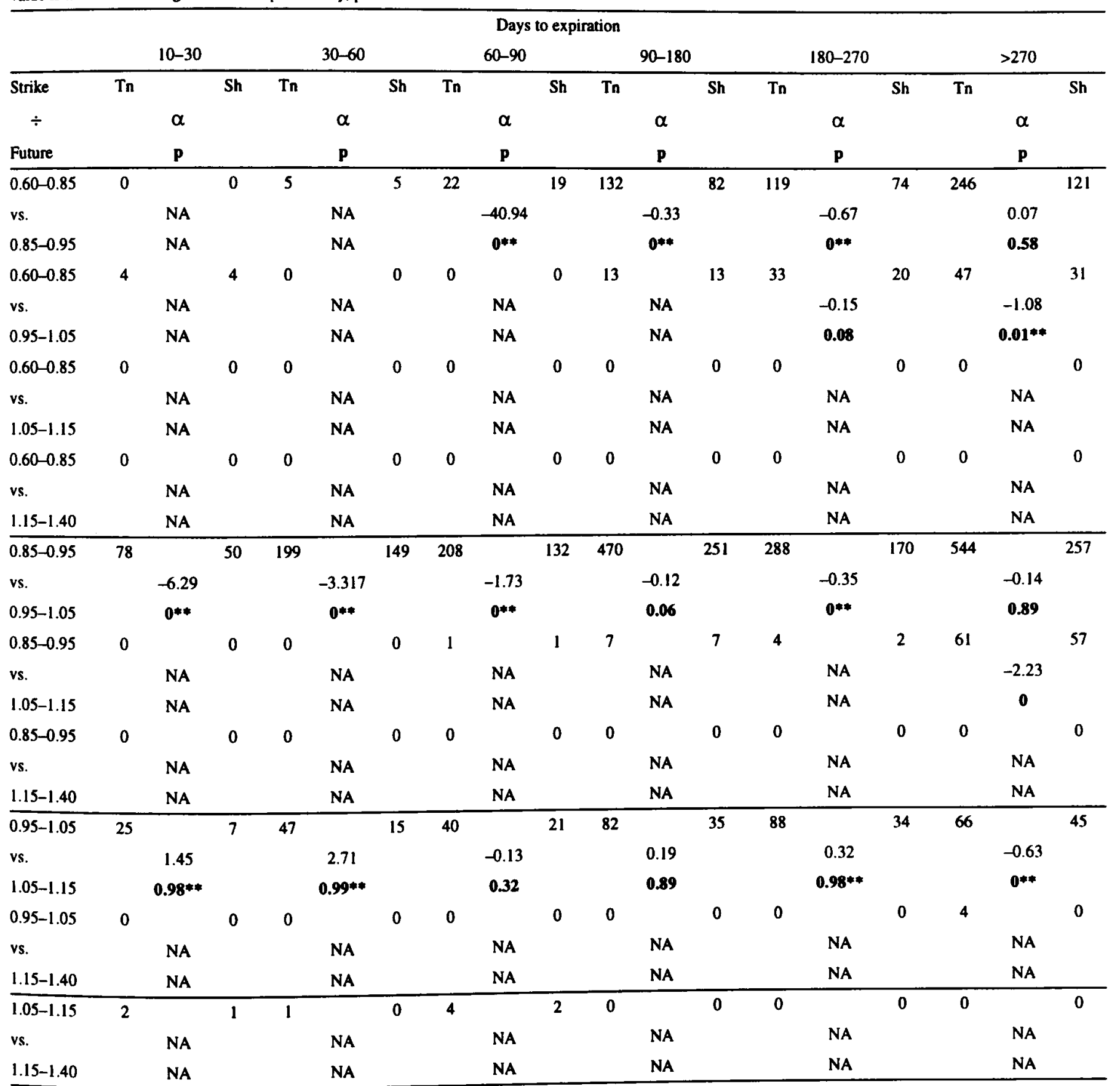

a. The ratio of strike price and future price headings would revert for a call (i.e. out-of-the-money becomes in-the-money and vice versa). However, the in-the-money put (call) volatility is the same as the out-of-the-money call (put) volatility because of the put call parity convention. Hence, we keep the headings consistent.

b. NA indicates a comparison with less than 20 pairs so that the economic and statistical signif cance tests are unneliable.

* Significantly different from 0.5 at the $10 \%$ level.

** Significantly different from 0.5 at the $5 \%$ level. 